\title{
Assessment of the Competitiveness of Economic Activities of the Region in Terms of Employment
}

\author{
Tatyana V. Sarycheva \\ Lyudmila P. Bakumenko \\ Mikhail N. Shvetsov \\ Mari State University, 424000, Yoshkar-Ola, Russia \\ Email: tvdolmatova@bk.ru
}

Doi:10.5901/mjss.2015.v6n3s7p119

\begin{abstract}
In the context of limited investment opportunities, it becomes important to study the competitiveness of economic activities, which represents one of the essential components of the study of the relations at the labour market, and also serves as an important reference point for the formation of regional economic policy and the strategies of business communities. In the article the authors describe the methodology of complex statistical assessment of prospectivity and competitiveness of the economic activities of the region, based on using the method of shift-components together with the coefficient of localization. This approach allows identifying the level (district, industrial or regional) at which the factors, determining the dynamics of the regional employment structure by economic activities, and consequently the level, at which the control actions should be focused to prevent destructive changes. The application of the suggested method was carried out for the Mari El Republic. As a result, the dynamics of employment of the region was traced in comparison to the Volga Federal District, and the key causes of changes in the employment structure were determined for economic activities. The activities, which the region specializes in, were identified. The method allowed defining the areas of economic development of the Mari El Republic and formulating the probability scenarios of economic development for the activities of various competitiveness levels. The versatility of the proposed methodological tools and their correspondence to the intended function substantiate the lawfulness of their use by other regions of both the Volga Federal District and the Russian Federation.
\end{abstract}

Keywords: employment structure by economic activities, region, method of shift-components, index of localization, probability scenarios of development

\section{Introduction}

The modern stage of socio-economic transformations is characterized by active search for the ways of solving regional development problems. Among them the problem of the formation of adequate and well-functioning regional labour markets is of primary importance. It is the regions with limited job opportunities and choice of vacancies, in which the labour market situation is characterized by greater intensity. Employment in a region is understood rather as a "conglomeration of anomalies" than as an integrated and internally coherent system. Unfortunately it is facilitated by the instability of the economy and the imbalance between the supply and demand of the workforce.

The Mari El Republic is a region without a clearly defined specialization (Sarycheva, Bakumenko, 2015). The shares of employed in various economic activities are approximately equal. Investment opportunities in the Mari El Republic are limited and do not allow simultaneous investments into all economic activities. Due to this fact, the concentration of resources is essential in those activities of the regional economy, which can become the points of economic growth, since they have certain potential. Stimulating tools of regional politics are recommended for the use in particular for the economic activities forming the basis of the regional economy, which will provide economic and social effect.

The development and implementation of the effective employment policy in a region are impossible without the identification of the basic competitive economic activities (Kolmakova, 2004), which in its turn involves the study of the current situation as well as the analysis of the dynamics of changes in the structure of employment in the region by economic activities (Moskovskaya, 1999). The category of "competitiveness" has different interpretations among both Russian and foreign specialists. Such researchers as M. Porter, K. Fleischer, B. Bensuan, A. Khasanova, I. Spriridonov, R. Fatkhutdinov, V. Petrov, O. Belousova, D. Lukyanenko, Y. Makogon and others were engaged in the study of 
competitiveness (Vlasenko, 2009). In general sense, competitiveness refers to the ability to outstrip others using your advantages to achieve the goals. Competitiveness of economic activities in the individual region requires the presence of competitive advantages over the similar activities of the district as a whole, which are expressed in the availability of the rational employment structure. The factors of competitiveness primarily include the resource factor (the number of employed) and the environment factor (the economic policy of the region).

Currently, the method based on the analysis of absolute and relative changes in the number of employed by activities is used at the level of both regions and districts in order to evaluate the changes in the employment structure. In this approach a decrease in the employment of population is unambiguously evaluated negatively, and an increase is respectively considered to be positive. At the same time, a comparison of the absolute and relative values only indicates unspecified involvement of the resource and environment factors in the mentioned process and does not allow measuring the contribution of each factor to the total change in employment. Taking into account the above mentioned, it seems reasonable to move the area of research in the field of the competitiveness of economic activities towards the development or application of the new methods for the measurement of quantitative and qualitative changes to the particular regions.

\section{Methods and Materials}

In order to identify economic activities with high employment potential, cross-section analysis of the economy was conducted in terms of employment. The method of shift-components was used as the basic method for research. This method allows analyzing and measuring the quantitative shifts in employment and dividing the total increment into three segments by determining the value of the influence of the district, industrial and regional factors (Milyaeva, 2001).

The change in the number of employed people in each economic activity of the region is influenced by (Sarycheva, 2012):

1. District component $($ Dis $)$, which reflects the trends of economic development at the district level and is determined as follows: $D i s=E_{i} \cdot T / 100$,

where ${ }^{E_{i}}$ - the number of employed in the $i$-th type of activity of the region in 2000;

$T$ - the rate of growth of employed in the district economy as a whole from 2000 till 2013

2. Industrial component ${ }^{(I n d)}$, which reflects the development trends of an individual economic activity. It is calculated using the following formula: $\operatorname{Ind}=E_{i} \cdot\left(T_{j} / 100-T / 100\right)$, where ${ }^{T_{j}}$ - the rate of growth of employed in the ${ }^{j}$-th economic activity of the district as a whole from 2000 till 2013

3. Regional component $(\mathrm{Reg})$, which reflects the influence of the regional factors. It is calculated as follows: $\operatorname{Reg}=E_{i} \cdot\left(T_{i} / 100-T_{j} / 100\right)$,

where $T_{i}$ - the rate of growth of employed in a certain economic activity of the region from 2000 till 2013.

The sum of the values of these components gives the value of the total change in the number of people employed in a particular industry of the region.

$R=$ Dis + Ind + Reg ,

where $R$ - the total change in the regional employment.

The method of the analysis of structural changes in employment was applied together with the coefficient of localization, calculation of which allowed distinguishing the industries by the level of competitiveness and identifying the most prospective industries. Integrated assessment was determined by the relative concentration of various industries in the local economy and dynamics. When calculating the coefficient of localization $\left.{ }^{(} K_{t i}\right)$ for each economic activity of the region, the following formula was used (Sarycheva, 2012):

$$
K_{l i}=\left(e_{i} / e\right) /\left(E_{i} / E\right) \text {, }
$$

where $e_{i}$ - the number of employed in the $i$-th activity of the region economy;

$e_{-}$the total number of employed in the region economy;

$E_{i}$ - the number of employed in the ${ }^{i}$-th activity of the district economy;

$E$ - the total number of employed in the district economy. 
The coefficient of localization $\left(K_{l_{i}}\right)$, which equals to 1.0, means that the region and the district have the same specific weight of the economic activity in terms of employment. If the coefficient of localization is greater than 1 , then this economic activity prevails in the regional economy (in comparison to the district as a whole). The basic economic activities refer to economic activities with the coefficient of localization which exceeds 1.251 . This means that the region begins to specialize in this particular sector of economy. It is these types of activity that are said to provide the export of goods and services beyond the region. The types of activity with the coefficient of localization in the range from 0.751 to 1.25 are the activities of local significance. They cover the needs of the internal market of the Republic. Together they form the current specialization of the region. All these activities are potentially meant to be maintained in the region. The activities, in which the region does not specialize, have the coefficient of localization below 0.75 (Milyaeva, 2001; R. Froeschle (2005).

The data on economic activities presented in the official collections of the Territorial Body of State Statistics of the Mari El Republic served as the information base of the research

\section{Results and Discussion}

A comparison of trends at the labour markets of the Volga Federal District (VFD) and the Republic of Mari El (RME) showed that in general the number of employed both in the whole district and in the region in the period from 2000 till 2013 had positive dynamics.

In the analyzed period employment in the district economy has slightly increased by $0.05 \%$ (7.1 thousand people), and in the RME the increase in the number of employed was over $1.05 \%$ (17.8 thousand people). While the employment situation in the district in recent years has been relatively stable, the state of employment in the region had reversed trend. This is evidenced by the growth rates of the analyzed indicator, the dynamics of which is presented in Figure 1 (Regions of Russia. Socioeconomic indicators, 2014).

The more detailed study of the course of employment changes by economic activities allowed identifying some disproportions in the regional dynamics in relation to the district one (Mari El, 2014). Having analyzed the indicators of the number of employed in the extreme periods of the time period under consideration, it may be noted that the maximum growth rate of the number of employed in the VFD from 2010 to 2013 was achieved in the following spheres: real estate transactions (275.1), construction (319.7\%) and wholesale and retail trade (735.4). The reduction in the number of employed occurred in 6 from 13 basic economic activities; the largest reduction characterized agricultural enterprises, for which the number of employed decreased by 709.0 thousand people. As for the RME, such economic activity as agriculture, by contrast, was stable enough in terms of the number of employed with respect to the extreme periods of study: the increment rate of this indicator was $540.0 \%$, and in the physical volume the number of employed in this economic activity increased by 24.2 thousand people (Table 1). But the main growth in the employment characterized this activity in 2001, when the number of employed in this sphere reached 61.2 thousand people. In the rest time period this indicator was characterized by decreasing trend.

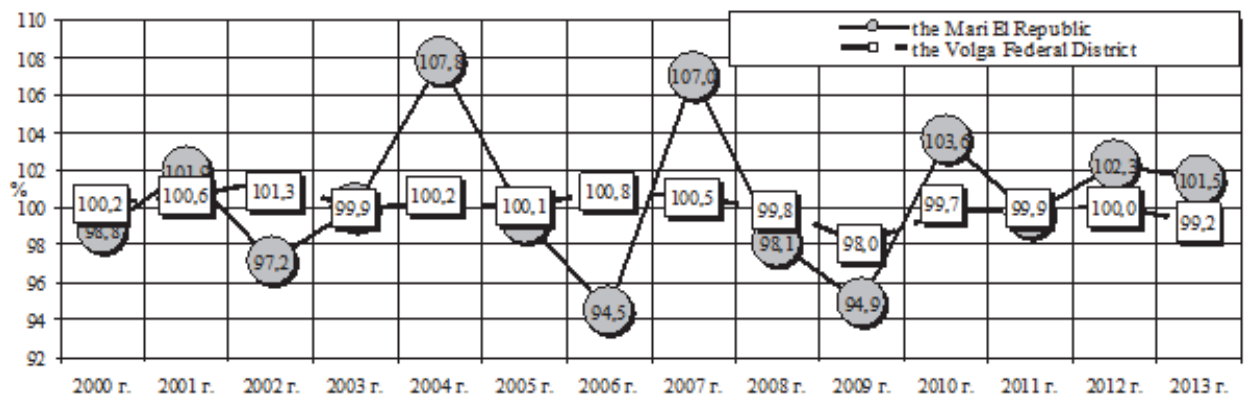

Figure 1 - Comparison of the dynamics of the growth rates of the number of employed in the VFD and the RME, 20002013

In the RME the growth of employment was observed in 10 from 13 basic economic activities. Significant growth (333.3\%) characterized mining operations, for which the number of employed increased by 0.7 thousand people. In the Volga Federal District, manufacturing and education appeared in the list of three most unclaimed spheres; the reduction of the number of employed in these areas amounted to 663.0 and 158.7 thousand people respectively. 
Table 1 - Changes in employment in the economy of the VFD and RME (by economic activity), 2013/2000

\begin{tabular}{|l|c|c|c|c|c|c|c|c|}
\hline \multirow{3}{*}{ Economic activity } & \multicolumn{3}{|c|}{ Volga Federal District } & \multicolumn{4}{|c|}{ Republic of Mari El } \\
\cline { 2 - 9 } & \multicolumn{2}{|c|}{ Thousand people } & \multicolumn{2}{|c|}{ Change } & \multicolumn{2}{|c|}{ Thousand people } & \multicolumn{2}{c|}{ Change } \\
\cline { 2 - 9 } & 2000 & 2013 & 2000 & 2013 & 2000 & 2013 & Thousand people & $\%$ \\
\hline Agriculture & 2326.8 & 1617.8 & -709.0 & -30.47 & 5.5 & 29.7 & 24.2 & 440.00 \\
\hline Mining operations & 208.6 & 167.4 & -41.2 & -19.75 & 0.3 & 1.0 & 0.7 & 233.33 \\
\hline Manufacturing & 3266.6 & 2603.6 & -663.0 & -20.30 & 59.8 & 69.3 & 9.5 & 15.89 \\
\hline Production and distribution of electricity, gas and water & 400.6 & 388.7 & -11.9 & -2.97 & 7.6 & 12.7 & 5.1 & 67.11 \\
\hline Construction & 832.1 & 1151.8 & 319.7 & 38.42 & 32.3 & 37.1 & 4.8 & 14.86 \\
\hline Wholesale and retail trade & 1696.2 & 2431.6 & 735.4 & 43.36 & 35.8 & 50.2 & 14.4 & 40.22 \\
\hline Hotels and restaurants & 212.7 & 245.9 & 33.2 & 15.61 & 4.0 & 6.9 & 2.9 & 72.50 \\
\hline Transport and communication & 987.8 & 1010.8 & 23.0 & 2.33 & 18.0 & 22.0 & 4.0 & 22.22 \\
\hline Real estate transactions & 777.0 & 1052.1 & 275.1 & 35.41 & 55.5 & 15.2 & -40.3 & -72.61 \\
\hline Education & 1365.5 & 1206.8 & -158.7 & -11.62 & 40.0 & 32.8 & -7.2 & -18.00 \\
\hline Healthcare & 967.6 & 939.3 & -28.3 & -2.92 & 17.1 & 23.8 & 6.7 & 39.18 \\
\hline Provision of other services & 439.1 & 459.0 & 19.9 & 4.53 & 28.6 & 13.4 & -15.2 & -53.15 \\
\hline Other activities & 729.3 & 942.3 & 213.0 & 29.21 & 20.1 & 33.3 & 13.2 & 65.67 \\
\hline Total & 14209.9 & 14217.1 & 7.2 & 0.05 & 324.6 & 347.4 & 22.8 & 7.02 \\
\hline
\end{tabular}

In order to distinguish the factors, which determined the increase in employment in the RME, at the first stage the district shift-component $($ Dis) was separated. For this purpose the data of the sixth column of the Table 1, containing information on the base number of employed in the region economy (in 2000), were multiplied by the level of growth in the district (100.05\%). The results are presented in the second column of the Table 2.

Table 2 - The district shift-component of the employment change in the economy of the RME

\begin{tabular}{|l|c|c|c|c|}
\hline \multirow{2}{*}{ Economic activity } & \multicolumn{2}{|c|}{ Dis } & \multirow{2}{*}{$R, \%$} & Ind + Reg,$\%$ \\
\cline { 2 - 3 } & Thousand people & $\%$ & & \\
\hline Agriculture & 0.00 & 0.05 & 440.00 & 439.95 \\
\hline Mining operations & 0.00 & 0.05 & 233.33 & 233.28 \\
\hline Manufacturing & 0.03 & 0.05 & 15.89 & 15.84 \\
\hline Production and distribution of electricity, gas and water & 0.00 & 0.05 & 67.11 & 67.05 \\
\hline Construction & 0.02 & 0.05 & 14.86 & 14.81 \\
\hline Wholesale and retail trade & 0.02 & 0.05 & 40.22 & 40.17 \\
\hline Hotels and restaurants & 0.00 & 0.05 & 72.50 & 72.45 \\
\hline Transport and communication & 0.01 & 0.05 & 22.22 & 22.17 \\
\hline Real estate transactions & 0.03 & 0.05 & -72.61 & -72.66 \\
\hline Education & 0.02 & 0.05 & -18.00 & -18.05 \\
\hline Healthcare & 0.01 & 0.05 & 39.18 & 39.13 \\
\hline Provision of other services & 0.01 & 0.05 & -53.15 & -53.20 \\
\hline Other activities & 0.01 & 0.05 & 65.67 & 65.62 \\
\hline Total & 0.16 & 0.05 & 7.02 & 6.97 \\
\hline
\end{tabular}

To evaluate the industrial effect, the base number of employed in each economic activity (the second column of the Table 2) was multiplied by the deviation of actual changes in the number of employed by economic activities (the sixth column of the Table 2) from the district change (increase or decrease) in the number of employed in the economy. The results are presented in the second and the third columns of the Table 3. 
Table 3 - The industrial shift-component of the employment change in the economy of the RME

\begin{tabular}{|l|c|c|c|c|}
\hline \multirow{2}{*}{ Economic activity } & \multicolumn{2}{|c|}{ Ind } & \multirow{2}{*}{ Ind + Reg, $\%$} & \multirow{2}{*}{ Reg, \% } \\
\cline { 2 - 3 } & Thousand people & $\%$ & & \\
\hline Agriculture & -1.68 & -30.52 & 439.95 & 470.47 \\
\hline Mining operations & -0.06 & -19.80 & 233.28 & 253.08 \\
\hline Manufacturing & -12.17 & -20.35 & 15.84 & 36.18 \\
\hline Production and distribution of electricity, gas and water & -0.23 & -3.02 & 67.05 & 70.08 \\
\hline Construction & 12.39 & 38.37 & 14.81 & -23.56 \\
\hline Wholesale and retail trade & 15.50 & 43.31 & 40.17 & -3.13 \\
\hline Hotels and restaurants & 0.62 & 15.56 & 72.45 & 56.89 \\
\hline Transport and communication & 0.41 & 2.28 & 22.17 & 19.89 \\
\hline Real estate transactions & 19.62 & 35.35 & -72.66 & -108.02 \\
\hline Education & -4.67 & -11.67 & -18.05 & -6.38 \\
\hline Healthcare & -0.51 & -2.98 & 39.13 & 42.11 \\
\hline Provision of other services & 1.28 & 4.48 & -53.20 & -57.68 \\
\hline Other activities & 5.86 & 29.16 & 65.62 & 36.47 \\
\hline Total & 36.38 & 11.21 & 6.97 & -4.23 \\
\hline
\end{tabular}

The Table 4 shows all values of the components of employment by economic activities in the RME for 13 years: from 2000 through 2013.

Table 4 - The components of the employment changes in the economy of the RME, thousand people

\begin{tabular}{|c|c|c|c|}
\hline \multirow{2}{*}{ Economic activity } & \multicolumn{3}{|c|}{ Shift-components } \\
\cline { 2 - 3 } & Dis & Ind & Reg \\
\hline Agriculture & 0.00 & -1.68 & 25.88 \\
\hline Mining operations & 0.00 & -0.06 & 0.76 \\
\hline Manufacturing & 0.03 & -12.17 & 21.64 \\
\hline Production and distribution of electricity, gas and water & 0.00 & -0.23 & 5.33 \\
\hline Construction & 0.02 & 12.39 & -7.61 \\
\hline Wholesale and retail trade & 0.02 & 15.50 & -1.12 \\
\hline Hotels and restaurants & 0.00 & 0.62 & 2.28 \\
\hline Transport and communication & 0.01 & 0.41 & 3.58 \\
\hline Real estate transactions & 0.03 & 19.62 & -59.95 \\
\hline Education & 0.02 & -4.67 & -2.55 \\
\hline Healthcare & 0.01 & -0.51 & 7.20 \\
\hline Provision of other services & 0.01 & 1.28 & -16.50 \\
\hline Other activities & 0.01 & 5.86 & 7.33 \\
\hline Total & 0.16 & 36.38 & -13.74 \\
\hline
\end{tabular}

As it is shown in the Table 4, the effect of the district growth, i.e. the increase in the number of jobs due to the district shift-component, amounted to 0.16 thousand people in the RME. The total increase in the workforce in the region equaled (for 2000-2013) 22.8 thousand people.

The increase in the number of jobs by 22.74 thousand became the result of the combined action of the industrial and regional factors. The effect of industrial growth of the number of jobs was 36.38 thousand people. This is primarily construction, wholesale and retail trade and real estate transactions. The total increase in the number of staff in these industries due to the industrial component amounted to 47.52 thousand people. At the same time this component had the negative impact on such activities as agriculture, mining operations, manufacturing, production and distribution of electricity, gas and water, education and healthcare, the number of employed in which reduced due to the industrial component by $1.68 ; 0.06 ; 12.17 ; 0.23 ; 4.67$ and 0,51 thousand people respectively.

The analysis of the data showed that the regional factor has a dominant influence on the employment change in most activities of the economy of the RME. Thus, the effect of the regional policy had a positive impact on eight of thirteen base types of economic activities: agriculture; mining operations; manufacturing; production and distribution of electricity, gas and water; hotels and restaurants; transport and communication; healthcare as well as other activities. At the same time, the positive regional shift-component significantly exceeds the negative industrial component, which 
allowed these spheres to increase the number of involved workforce.

The regional shift-component has the largest negative impact on such sphere of activity as real estate operations, renting and provision of services (-59.95 thousand people), which was characterized by the largest possible influence of the industrial factor (19.62 thousand people). This activity lost 40.3 thousand employees. The situation, which is similar in effect (the regional factor is negative, the industrial one is positive) and even more contrast in terms of ratio, was observed in the sphere of provision of other services, where the number of employees decreased by 15.2 thousand people. The situation in wholesale and retail trade is similar. However, the high value of the industrial component still allows this economic activity to develop dynamically and to increase the number of staff (14.4 thousand people).

The negative sign characterized the industrial and regional components in the analyzed period only in the sphere of education, where the number of employed in the considered period decreased by more than 7 thousand jobs.

Summarizing the above mentioned, we should note that the adaptation of the method of shift-components to the peculiarities of the regional economy should be definitely considered as an important contribution to the expansion of tools for quantitative analysis of the structural changes in employment Using this method allows us to re-evaluate the quantitative shifts in employment and to decompose the total reduction into shares. Taking into account that the contribution of the regional factors accounted for only «- 4,26\%» (and $100.05 \%$ and $11.21 \%$ for the district and industrial factors respectively), the local policy should be regarded as sufficiently effective.

The calculation of the coefficients of localization showed that the base activities in the RME may include: production and distribution of electricity, gas and water $\left(K_{l_{i}}=1,34\right)$, construction $\left({ }^{K_{l i}}=1,32\right)$ and other activities $\left(K_{l i}\right.$ $=1,45$ ), which primarily include public administration and military security, social insurance and financial activity (Figure 2).

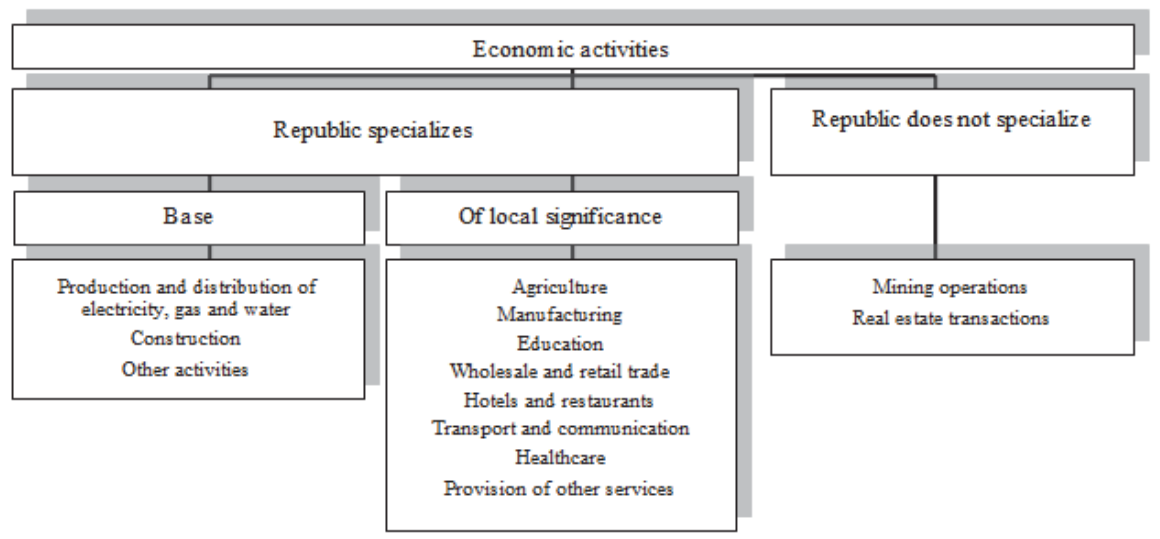

Figure 2 - The classification of the economic activities in the RME by the values of the index of localization, 2013

Agriculture; manufacturing; wholesale and retail trade; hotels and restaurants; transport and communication; healthcare; provision of other services are the activities of local significance and should be maintained in the region.

In spite of the fact that in the analyzed period the companies, which performed mining operations, were characterized by one of the most significant staff influxes in terms of growth rate, this type of activity along with real estate transactions are still not prospective for investment since they cannot cover even the needs of the internal market of the Republic. The classification of economic activities by the level of competitiveness, using the following gradation, is of interest:

1. Strong -activities which are developing in the RME faster than in the VFD.

2. Lagging - activities which are developing in the RME slower than in the VFD.

3. Limitedly developing - activities for which the decline in the RME is slower than in the VFD.

4. Depressive - activities in which the staff reduction in the RME exceeds the reduction in the VFD.

The classification of economic activities by the level of competitiveness is presented in the Table 5. 
Table 5 - The classification of the economic activities in the RME

\begin{tabular}{|l|l|l|}
\hline Groups of activities & Names of activities \\
\hline \multirow{3}{*}{ Base } & Strong & $\begin{array}{l}\text { Production and distribution of electricity, gas and water } \\
\text { Other activites }\end{array}$ \\
\cline { 2 - 3 } & Lagging & Construction \\
\hline \multirow{3}{*}{ Of local signinficance } & Strong & Agriculture; Healthcare; Hotels and restaurants; Manufacturing; Transport and communication \\
\cline { 2 - 3 } & Lagging & Wholesale and retail trade \\
\cline { 2 - 3 } & Depressive & Education; Provision of other services \\
\hline \multirow{2}{*}{ Region does not specialize in in } & Strong & Mining operations \\
\cline { 2 - 3 } & Depressive & Real estate transactions \\
\hline
\end{tabular}

The Table 6 shows the recommended actions of the economic policy with respect to each group of economic activities of the region.

Table 6 - Possible scenarios of the regional economic policy for the economic activities of various levels of competitiveness

\begin{tabular}{|l|l|l|}
\hline \multicolumn{2}{|l|}{ Type of the economic activity } & Possible scenario of economic policy \\
\hline \multirow{2}{*}{$\begin{array}{l}\text { Types of activity the region } \\
\text { specializes in }\end{array}$} & Strong & to establish and facilitate strengthening of the factors, conductive to their development \\
\cline { 2 - 3 } & Lagging & to work out the measures aimed at the development of the lagging but prospective activities \\
\cline { 2 - 3 } & Depressive & to adopt the development programmes for education and the sphere of social services \\
\hline \multirow{2}{*}{$\begin{array}{l}\text { Types of activity the region does not } \\
\text { specialize in }\end{array}$} & Strong & to stimulate the local factors of development \\
\cline { 2 - 3 } & Depressive & no support is needed \\
\hline
\end{tabular}

\section{Conclusion}

The methodology for comparison of economic activities in terms of employment, based on using the method of shiftcomponents together with the coefficient of localization, made it possible to divide the economic activities of the region into the base activities, the activities of local significance and the activities, which the RME does not specialize in, as well as allowed identifying the strong, lagging and depressive areas of activity.

Each group of economic activities has its own probability scenario of economic policy. For the strong activities of the regional specialization (production and distribution of electricity, gas and water; other activities; agriculture; healthcare; hotels and restaurants; manufacturing; transport and communication) it is necessary to establish and facilitate the strengthening of the factors, conductive to their development. The development of the lagging activities (construction; wholesale and retail trade) requires working out the measures aimed at the development of the lagging but prospective activities. Adopting the development programmes for education and the sphere of social services will gain momentum to the development of the depressive activities of the regional specialization. Stimulation of the local factors will contribute to the development of mining operations. The sphere of real estate operations requires no support (Sarycheva, Shvetsov, 2015).

The study of the employment structure by economic activities is an essential part of the analysis and evaluation of the effects of structural shifts in the economy of both individual regions and the districts and Russia as a whole. Therefore the development of effective policy should be supported by the measures, primarily connected with the shifts in the employment structure by the economic activities. The versatility of the proposed methodological tools and their correspondence with the target destination justify the lawfulness of the use of the given methodology in the other regions of the Volga Federal District.

\section{Acknowledgment}

The study was carried out with financial support from the Russian Foundation for Humanities within the project for conducting research "Demographic and economic potential of the region: macrosystem approach", the project No. 15-0200567.

\section{References}

Froeschle, R. (2005). What to do With All This Data? The Role of Economic Base Analysis in Regional Economic Developmen. [Online] 
Available: http://www.texasindustryprofiles.com/apps/locquot/LQ_Docs/Updated\%20Economic\%20Base\%20Analysis\%202005. doc

Kolmakova, I.D. (2004). Social and economic features of regional labor. Bulletin of the Orenburg state university. No. 2, 2004, 102-105

Mari El. (2014). Stat. coll. Territorial authority of Federal State Statistics Service in the Republic of Mari El. 419 p.

Milyaeva, L.G. (2001). Analysis of structural changes in employment of the population by method shift components. [Online] Available: http://elib.altstu.ru/elib/books/Files/2001-02/19/pap 19.html.

Moskovskaya, A. (1999). High-quality and quantitative shifts in the sphere economy employments. Economy questions. No. 11, 1999, 114-127.

Regions of Russia. Socioeconomic indicators (2014). Stat. coll. Rosstat. 900 p.

Sarycheva, T.V. (2012). Comparative Analysis of Structural Changes in The Population Employment of the Republic Of Mari El. No. 3 (2); 2015, 170-176

Sarycheva, T.V., Bakumenko, L.P. (2015). The Conceptual Approaches to the Analysis of the Labour Market and Employment. Review of European Studies; Vol. 7, No. 8; 2015, 343-355. DOI: 10.5539/res.v7n8p343

Sarycheva, T.V., Shvetsov, M.N. (2015). Statistical Approaches to the Evaluation of the Demand and Supply at the Labour Market Based on Panel Data. Review of European Studies; Vol. 7, No. 8; 2015, 356-367. DOI:10.5539/res.v7n8p356

Vlasenko, A.A. (2009) Methodology of an assessment of competitiveness of branch. [Online] Available: http://www.rusnauka.com/ 29_DWS_2009/Economics/53408.doc.htm. 